\title{
Study on varability between dehusked coconuts using principal component analysis
}

\section{Asha Monicka, Pandiarajan and Ganapathy}

See end of the Paper for authors' affiliation

Correspondence to :

Asha Monicka

Department of Food and Agricultural Process

Engineering, Tamil Nadu Agricultural University,

Coimbatore (T. N.) India

Email : asha.oct11@gmail.com
- ABSTRACT : Marketing of coconuts differs from that of other fresh fruits due to natural durability of coconuts, which are sold as fresh tender nuts as well as matured water nuts and dry nuts. Most widely indirect mode of disposal of coconuts is adopted by coconut farmers. In India mostly coconuts are segregated by manual inspection. This research concerns about grades of dehusked coconut. Principal component analysis was done to find the principal components in the different grades of dehusked coconut. The result indicate that weight of nut, weight of fresh kernel and the major diameter of the coconut are principal components needed to grade the dehusked coconut.

- KEY WORDS : Varability, Dehusked, Principal component analysis

- HOW TO CITE THIS PAPER : Monicka, Asha, Pandiarajan and Ganapathy (2018). Study on varability between dehusked coconuts using principal component analysis. Internat. J. Agric. Engg.,11(2):397-399, DOI: 10.15740/HAS/JJAE/11.2/397-399.Copyright@ 2018: Hind Agri-Horticultural Society. 